\title{
In Bloom: Gender Differences in Preferences among Adolescents*
}

\author{
Anna Dreber ${ }^{a}$, Emma von Essen ${ }^{b}$, and Eva Ranehill ${ }^{c}$
}

SSE/EFI Working Paper Series in Economics and Finance

No 734

This version: July 2012

First version: February 2011

\begin{abstract}
We look at gender differences among adolescents in Sweden in preferences for altruism, risk and competition. We find that girls are more altruistic and less risk taking than boys. No gender differences are found comparing competitive performance with non-competitive performance in either a verbal or a mathematical task. Boys and girls are also equally likely to self-select into competition in the verbal task, but boys are significantly more likely to choose to compete in math. However, this gender gap diminishes and becomes non-significant when we control for performance beliefs relative to others, indicating that some of the gender gap in our sample is not due to preferences for competition per se.
\end{abstract}

Keywords: competitiveness; risk preferences; altruism; adolescents; gender differences;

experiment

JEL codes: C91; D03; J16

\footnotetext{
${ }^{*}$ We are grateful for comments from Johan Almenberg, Simon Gächter, Uri Gneezy, Magnus Johannesson, Christoph Mathys, Astri Muren, Robert Östling, David G. Rand, Roberto Weber and seminar participants at WAPPP at the Harvard Kennedy School, MOVE Workshop on Gender Differences in Competitiveness and Risk Taking, Stockholm School of Economics and Stockholm University, as well as help with the data collection from Aron Backström, Peter Gerlach and Karin Hederos Eriksson. Financial support from the Jan Wallander and Tom Hedelius Foundation and the Carl Silfvén Foundation (E.R.) is gratefully acknowledged, as well as financial support from the Swedish Council for Working Life and Social Research (FAS).

a Department of Economics, Stockholm School of Economics. Email: anna.dreber@hhs.se

b Department of Economics, Stockholm University. Email: emma.vonessen@ne.su.se

c Department of Economics, University of Zürich. Email: eva.ranehill@econ.uzh.ch
} 


\section{Introduction}

Women today are in many countries at least as likely as men to pursue higher education and to participate in the labor market. Yet, the wage gap and the segregation in the labor market persist. One possible cause of gender differences in labor market outcomes is that men and women differ in terms of economic preferences. Gender differences in preferences are often studied through laboratory experiments, and in these it is often found that men are less altruistic but more risk taking and competitive than women (see, e.g., Eckel and Grossman 2008a; 2008b; Croson and Gneezy 2009; Bertrand 2010; Engel 2011).

In this paper we explore the gender gap in preferences for altruism, risk and competition among Swedish adolescents aged about 16-18 years. Little is known about the development of the gender gap in economic preferences, and to what extent adolescents exhibit the same type of gender differences in preferences as adults do. Many scholars have recently argued that gender differences in preferences may explain part of the gender gap in labor market outcomes. If so, it is relevant to also assess gender differences before individuals enter the labor market. Many important decisions that have implications for labor market outcomes, such as education choices, are taken during adolescence.

We find that adolescent girls are more altruistic and less risk taking than boys. We find no gender difference in performance change under a competitive setting in comparison to a noncompetitive setting, in either a mathematical or a verbal task. Boys and girls are further equally likely to choose to compete in the verbal task, but boys are significantly more likely to choose to compete in the mathematical task. However, the gender gap in choosing to compete in the mathematical task diminishes and is no longer significant when we control for relative performance beliefs.

We thus find rather similar gender differences in preferences among adolescents as what is typically found among adults. Assuming that the gender gap in preferences has implications for male and female education and career choices, this suggests that policies aimed at addressing labor market segregation by gender could start well before labor market entry.

Previous work on adolescents has studied some of these preferences in isolation: no previous study explores gender differences in all three preferences while also varying the task used in competitiveness. Our study indicates that among adolescents, the gender gap in competitiveness is not always present, and when it is, it may largely be due to other factors than a gender gap in preferences for competition per se. This result may be due to the setting 
in which these adolescents are studied: our study takes place in Sweden, a country which typically scores high on indices of gender equality. ${ }^{1}$ Thus to what extent our findings are generalizable to other countries remains to be explored. It is interesting to note that even though there is no gender difference in preferences for competition per se; girls are more altruistic and less risk taking than boys also in Sweden.

There is some evidence suggesting that the preferences studied in this experiment are correlated with labor market outcomes, and in particular that gender differences in social preferences, risk preferences and competitiveness may contribute to explaining the gender gap in labor market outcomes (see e.g. Bertrand 2010 for further discussion). For example, Fortin (2008) finds that four different non-cognitive traits among young employees, including a measure related to competitiveness and a measure related to altruism, can explain some of the gender gap in wages. Individuals that display more competitiveness and less altruism tend to earn more. There are also studies illustrating the connection between risk preferences and the labor market. Manning and Swaffield (2008) explain some of the gender gap in earnings with a set of psychological factors, including attitudes toward risk and competition. ${ }^{2}$ Bonin et al. (2007) find that individuals who self-report that they are less willing to take risks also work in occupations with more stable earnings, which tend to pay less on average due to compensating wage differentials. Though quantitatively small, a related effect is found in Manning and Saidi (2010) who find that there are fewer women in occupations and establishments that use variable pay instead of fixed pay contracts in Britain. ${ }^{3}$ Finally, Flory et al. (2010) test the relationship between labor market choices and competitiveness directly in a large scale, randomized field experiment. They find that women are less likely than men to choose to apply to jobs with highly competitive compensation regimes, but only if the domain of the job has a male stereotype.

We study the gender gap in altruism among adolescents in a dictator game. A recent metaanalysis of dictator game giving among adults finds that women are more altruistic than men (Engel 2011). There are by now also a number of studies on gender differences in altruism among children and adolescents. As with the adult literature, some of these studies find that girls are more altruistic (Harbaugh et al. 2003; Gummerum et al. 2010) whereas other studies find no gender gap (Benenson et al. 2007; Blake and Rand 2010) and one recent study finds

\footnotetext{
${ }^{1}$ However, among younger children, Cárdenas et al. (2012) find cross-country differences in the gender gap in preferences that cannot easily be explained by differences in overall gender equality.

${ }^{2}$ However, human capital factors are the most important variable explaining the gender wage gap.

${ }^{3}$ Dohmen et al. (2011) also find that risk preferences elicited from lab measures have a significant and positive, albeit low, predictive power for labor market behavior.
} 
that girls are less altruistic (Fehr et al. 2011). ${ }^{4}$ Moreover, when it comes to social preferences more generally, adolescent girls are typically found to be more inequality averse and boys more efficiency concerned (Almås et al. 2010; Sutter et al. 2010; Fehr et al. 2011; Martinsson et al. 2011). In order to study altruism among adolescents, we let participants play a dictator game where the recipient is a charity.

We also explore the gender gap in risk preferences. Among adults, women are typically found to be less risk taking than men. Previous literature on children finds either no gender gap (Harbaugh et al. 2002), or that boys are more risk taking than girls (Cárdenas et al. 2012; Borghans et al. forthcoming, Sutter et al. forthcoming). ${ }^{5}$ However, context or sample selection also seems to influence the gender gap in risk taking. Booth and Nolen (2012) look at single sex and mixed schools and find that in this sample of children around 15 years old, boys are more risk taking than girls in mixed schools but that there is no gender gap when comparing boys to girls from single sex schools. Girls are also more risk taking when assigned to all-girl groups than when assigned to mixed groups. Moreover, Cárdenas et al. (2012) find a smaller gender gap in risk taking among children in Sweden than in Colombia, suggesting that the gender equality of the country might be a good indicator of the size of the gender gap. In a similar vein, Gong and Yang (2012) find a smaller gap among adults in a matrilineal society compared to a patriarchal society in China. In this study we measure risk preferences in two ways. Our main measure consists of six choices where individuals choose between a lottery in the form of a coin flip that gives SEK 100 or 0 with equal probability and a safe option where the certain monetary amount increases successively in (from SEK 20 to 75). ${ }^{6}$ We also use a survey question where individuals are asked to self-report their general risk taking propensity. This measure has been shown to correlate with both risk taking in an incentivized experiment and with gender (Dohmen et al. 2011).

Competitiveness is typically measured as either the change in performance in a competitive setting compared to a non-competitive setting, or as a preference for competition, such as selfselecting into a tournament instead of a piece-rate payment scheme. Previous studies have found that if there is a gender gap in any of these measures, men and boys are more competitive (Gneezy et al. 2003; Gneezy and Rustichini 2004a; Niederle and Vesterlund

\footnotetext{
${ }^{4}$ However, Blake and Rand (2010) find that girls are more likely to give something compared to nothing than boys. The result found in Fehr et al. (2011) may partly be due to a gender difference in inequality aversion. Girls in their study are more likely than boys to choose an allocation of $(1,1)$ over $(1,2)$, but they are also more likely to choose $(1,1)$ over $(2,0)$.

${ }^{5}$ Harbaugh et al. (2002) have the smallest sample of the aforementioned studies on risk taking (129 children aged 5-13 and 58 children aged 14-20).

${ }^{6}$ When conducting the study SEK 7 corresponded to about USD 1.
} 
2007; Sutter and Rützler 2010; Datta Gupta et al. in press). However, the gender gap can be influenced by both the task performed and the sample in which competitiveness is studied. For example, Gneezy and Rustichini (2004b), Grosse and Riener (2010), Günther et al. (2010) and Shurchkov (2012) find that the gap in competitiveness varies or can even be reversed depending on the task performed and the time constraint, whereas Wozniak et al. (2010) find no effect of tasks. Yet other studies find that the existence of a gender gap in competitiveness varies with the type of sample studied (Booth and Nolen 2009; Gneezy et al. 2009; Andersen et al. 2010; Zhang 2010). For example, Gneezy and Rustichini (2004a) find that in Israel boys but not girls are competitive when it comes to performance change in running, whereas Dreber et al. (2011) and Cárdenas et al. (2012) find no gender gap in Sweden and Colombia with this measure in the same task. In this paper we explore the role of both performance change and self-selection into a competitive setting, in two different tasks: a mathematical task and a verbal task.

In sum, we find that adolescent girls are more altruistic and less risk taking than boys. When it comes to competitiveness the only significant gender difference is that boys are more competitive when it comes to choosing to compete in math. However, this gender gap disappears once we control for performance beliefs relative to others, indicating that confidence plays an important role for competitiveness among adolescents.

The outline of our paper is the following. We present the experimental setup in section 2, and move on to our results in section 3 . We finish by a discussion in section 4 .

\section{Experimental setup}

The study was conducted in nine school classes in five high schools in the Stockholm area during the fall of 2009. We contacted all schools in the cities of Stockholm, Uppsala and Västerås. Though we may have some selection regarding which schools that decided to participate, participation at the student level was compulsory. ${ }^{7}$ The school classes include a mix of different educational specializations. ${ }^{8}$ A total of 216 adolescents aged on average 17

\footnotetext{
${ }^{7}$ The result for the gender gaps reported does not differ between schools, tested in a regression frame work.

${ }^{8}$ The Swedish high school is optional and the students can choose programs with different specializations. Specialization does not seem to explain our results when controlled for in a regression frame work.
} 
years (min 15 and max 19 years old) in class years 10-12 participated in the study. ${ }^{9}$ Half of the participants were female.

The experiment consisted of three parts conducted in the classroom, measuring competitiveness, altruism and risk preferences. The participants first competed in a mathematical task (simple arithmetics) and a verbal task (word search). They then participated in a dictator game and finally in a risk task. The participants were informed that each of the three parts consisted of a chance to earn money. One of the three parts would be randomly selected for payment, and the amount of money they could earn depended on the outcome of the choices they made in this part. After completing all parts the participants were given a survey with additional questions.

The order of the competitive tasks was randomly chosen between classes and each task consisted of three stages. The participants did not get any feedback about their performance in any stage. In the first stage, a piece-rate scheme, the participants were told that they had two minutes to solve as many exercises as possible, for which they would be given SEK 3 each. In the second stage, a tournament, the participants were again told that they would get two minutes to solve exercises, but that they now would be randomly paired with three other individuals in the class who solved the same type of task, and that if they solved more or the same amount of exercises as these other individuals, they would get SEK 12 per exercise, whereas if they solved fewer exercises they would get SEK 0. In the third stage, the participants were told that they were to solve exercises for another two minutes, and that they now could choose whether they wanted to be given points according to the piece-rate scheme or the tournament (where they would again compete against three random other individuals in their class). Our measure of reaction to competition is the absolute change in performance between the first and second stages. The choice in the third stage gives us a measure of competitiveness as a preference for competition. After the competitiveness task was over, we asked the participants to guess where in the performance distribution of their class they believed themselves to be, for both the piece-rate scheme and the forced competition. This allows us to measure over- and underconfidence as the discrepancy between performance beliefs and the actual performance of a participant. We focus on the relative performance beliefs from the forced competition since this is more competition specific.

\footnotetext{
${ }^{9}$ Class years 10-12 represent the Swedish "gymnasium" (high school). Among the participants, 56 attended the $10^{\text {th }}$ year, 95 the $11^{\text {th }}$ and 50 the $12^{\text {th }} .15$ students attended a mixed class with students from years 10 and 11 . For these students we have no information about which year they actually attended at the moment of the study.
} 
Next the participants took part in a dictator game, where they were asked to distribute SEK 50 between themselves and a well-known charity organization. ${ }^{10}$ They were informed that if this part was selected for payment the money they gave to the charity would be sent by us to the charity at the end of the study. The amount that the participants give to the charity is our measure of altruistic behavior.

The last part was a risk task consisting of six choices where the participants could choose between a lottery in the form of a coin flip that gives SEK 100 or 0 with equal probability and a safe option where the certain amount increases successively in points (from SEK 20 to 75). Our first measure of risk preferences relies on the unique switching point where the individual switches from preferring the lottery to preferring the safe option. This measure excludes inconsistent participants, i.e. participants with multiple switching points. ${ }^{11}$ To further analyze risk preferences we include a survey question where the participants are asked to self-report their general risk taking propensity on a scale from 0 to 10 , where 10 is "very risk taking” and 0 is “not risk taking at all”. This second measure of risk preferences is not incentivized.

After the three parts of the study were conducted, a survey was included in order to measure beliefs concerning the different tasks, self-reported risk taking as well as other variables. ${ }^{12}$ In the end, one part was randomly selected for payment and the money was handed out in private in cash to the participants.

To summarize; we analyze altruistic behavior via a dictator game; risk preferences through incentivized choices over lotteries and safe options as well as self-reported risk taking; and competitiveness as performance change in a mathematical task and a verbal task, and as the choice to compete or not in the two tasks. We further look at additional measures such as relative performance beliefs.

\section{Results}

This section consists of three parts. We start by studying gender differences in altruism, followed by an analysis of risk preferences. We then explore competitiveness in the two tasks using the two measures of competitiveness. When exploring competitive preferences we

\footnotetext{
${ }^{10}$ The name of the charity organization was the Swedish section of "Save the children".

${ }^{11} 14$ of our participants are inconsistent. We therefore also analyze risk taking as the number of times a person chooses the risky option compared to the safe, in order to have a measure that includes the inconsistent participants. Using this measure of risk preferences in our analysis does not change our results. There is no gender difference in the proportions of inconsistent participants $(\mathrm{p}=0.102)$.

${ }^{12}$ We collected a variety of variables (the full survey is available from the authors on request). In this paper we use class (year), birth month, height, GPA, and life satisfaction (scale 0-10).
} 
control for relative performance beliefs and risk preferences. ${ }^{13}$ All tests of the means throughout the paper are analyzed using the non-parametric Mann-Whitney test and a twosided t-test. Only the p-values for the Mann-Whitney tests are displayed unless the tests give different results, in which case both results are reported. ${ }^{14}$

\subsection{Altruism}

Girls are significantly more altruistic than boys in our sample of adolescents $(p=0.014)$. Girls give on average SEK 29 and boys SEK 23 out of SEK 50 to the charity organization that is the recipient in our dictator game (see table 1$){ }^{15}$

Table 1. Altruism.

\begin{tabular}{lcc}
\hline \hline & $\mathbf{N}$ & Average donation \\
\hline Boys & 107 & 23.20 \\
Girls & 109 & 29.32 \\
p-value & - & 0.014 \\
\hline \hline
\end{tabular}

\subsection{Risk preferences}

In this section we explore the gender gap in risk preferences measured from incentivized lotteries and self-reported non-incentivized risk taking. Analyzing the incentivized risk task we corroborate most previous findings that boys are more risk taking than girls. The average certainty equivalent to the lottery with equal probabilities of winning 100 and 0 is 45.2 for boys. For girls the certainty equivalent is significantly lower, 37.1 ( $p=0.002) .{ }^{16}$ Our second measure of risk taking, self-reported risk propensity, supports this pattern. On a scale from 0

\footnotetext{
${ }^{13}$ We also perform a regression analysis for each behavior using the control variables from the survey (class year, birth month, height, GPA, and life satisfaction). The female coefficient remains similar for all behaviors except altruism, where it is no longer significant. Most control variables are not significant. For those that are significant, we find the following correlations: altruism is negatively correlated with birth month (individuals born early are more altruistic) whereas it is positively correlated with class year and GPA. Risk taking is positively correlated with class year. Competitiveness as measured by the choice to compete in the verbal task is negatively correlated with GPA.

${ }^{14}$ We present the Mann-Whitney test since none of our variables are normally distributed when using a skewness and kurtosis test. We have also compared whether the distributions for each reported variable differ between boys and girls using a Kolmogorov-Smirnov test. The results are similar to those reported for mean values.

${ }^{15}$ A correlation analysis between all the behaviors we examine also shows that altruism is positively related to risk taking in the incentivized risk task $(\mathrm{p}<0.001)$, but not in the self-reported question. We also find no correlation between altruism and competitive choices ( $\mathrm{p}=0.255$ for math and $\mathrm{p}=0.479$ for word).

${ }^{16}$ The result is qualitatively similar when analyzing the number of risky choices instead of the switching point in order to include inconsistent individuals (those that switch back and forth between the lottery and the safe points). Girls are still less risk taking compared to boys ( $\mathrm{p}=0.007)$. Moreover, there is no gender difference in the variance of incentivized risk taking $(\mathrm{p}=0.210)$.
} 
to 10 boys rated their average risk propensity to 6.15, whereas girls averaged on 5.59 $(\mathrm{p}=0.026){ }^{17}$

Table 2. Risk preferences.

\begin{tabular}{lcccc}
\hline \hline & $\mathbf{N}^{*}$ & Average certainty equivalent & $\mathbf{N}$ & General risk \\
\hline Boys & 103 & 45.22 & 107 & 6.15 \\
Girls & 98 & 37.12 & 109 & 5.59 \\
p-value & - & 0.002 & - & 0.026 \\
\hline \hline
\end{tabular}

*One girl did not participate in this part and 14 participants made inconsistent choices.

\subsection{Competitiveness}

In this section we explore competitiveness as measured by absolute performance change and as the choice whether to compete or not. All participants took part in both the mathematical task and the verbal task. ${ }^{18}$ We also include an analysis where we control for relative performance beliefs and risk preferences.

\subsubsection{Performance and choice}

Table 3 compares the performance between boys and girls in the first stage (a piece-rate scheme) and the second stage (a tournament). Studying performance in each stage separately, boys perform significantly better than girls in math in both stages, whereas there is no gender difference in performance in the verbal task. ${ }^{19}$

When it comes to absolute performance change, our first measure of competitiveness, we find no increase in performance under the competitive compensation scheme for either gender. In contrast to most previous literature measuring performance change, neither boys nor girls react to the competitive environment by increasing their performance comparing the second and the first stage. As a robustness check, we also analyze the relative performance change. ${ }^{20}$ This does not alter our results. Thus, there is no significant gender gap in competitiveness with this measure in either task.

\footnotetext{
${ }^{17}$ Our two risk measures are significantly positively correlated (Spearman’s rho=0.219, p=0.002).

${ }^{18}$ Randomly chosen, half of the classes performed the math task first and half performed the word task. A regression analysis suggests that the order of the tasks does not influence our results.

${ }^{19}$ Given that the gender gap in math performance in Sweden is small compared to many other countries (Guiso et al. 2008), this is a somewhat puzzling result. However, it might have to do with the specific sample in our study.

${ }^{20}$ Relative performance change is defined as ((performance in stage 2 - performance in stage 1)/performance in stage 1). We also conduct a quantile regression on absolute performance change and find no gender gap in math or word search in any part of the performance distribution.
} 
Table 3. Average performance, stage 1 and 2.

\begin{tabular}{lcccc|ccc}
\hline \hline & N & Math, stage 1 & Math, stage 2 & p-value & Word, stage 1 & Word, stage 2 & p-value \\
\hline Boys & 107 & 8.79 & 8.82 & 0.948 & 8.79 & 8.57 & 0.546 \\
Girls & $109 *$ & 7.31 & 7.44 & 0.510 & 8.74 & 8.61 & 0.542 \\
P & & 0.010 & 0.020 & - & 0.524 & 0.952 & - \\
\hline \hline
\end{tabular}

*One girl had to leave the class room and did not participate in the first part of the word task.

When it comes to the choice of competing or not, we find a significant gender gap in math but not in word search, although the point estimate goes in the same direction for both tasks (see table 4). ${ }^{21}$ In math, 38 (36\%) of the boys choose to compete compared to 18 (17\%) of the girls $(\mathrm{p}=0.001)$. The corresponding numbers in word search are 34 (33\%) and $29(28 \%)$ respectively $(\mathrm{p}=0.356){ }^{22}$ The difference in gender gaps between the two tasks is mainly due to girls choosing differently across the two tasks: the share of girls choosing to compete in the verbal task is significantly larger than the share choosing to compete in the math task $(p=0.050)$, whereas the proportion of boys competing is stable across the two tasks $(p=0.701)$.

Table 4. Percentage choosing to compete in stage 3.

\begin{tabular}{lccccc}
\hline \hline Task\Gender & $\mathbf{N}$ & \% competing math & $\mathbf{N}$ & \% competing word & p-value \\
\hline Boys & 106 & 0.358 & 105 & 0.333 & 0.701 \\
Girls & 109 & 0.165 & 109 & 0.275 & 0.050 \\
$\mathbf{P}$ & - & 0.001 & - & 0.356 & \\
\hline \hline
\end{tabular}

\subsubsection{Relative performance beliefs and risk preferences}

Due to the gender gap in performance in the math task in each of the two stages, all or part of the observed gender gap may be due to participants incorrectly or correctly anticipating their probability of winning the tournament should they choose to participate.

We start by exploring over- and underconfidence. Table 5 reports the number of correct guesses regarding relative performance, divided by task and gender. Relative to their performance, we find that girls are underconfident in terms of their performance beliefs (Math: $\mathrm{p}<0.001$ : Word: $\mathrm{p}<0.001$ ), whereas there is some evidence that boys are underconfident in the mathematical task but not in the word task (Math: $p=0.065$ : Word:

\footnotetext{
${ }^{21}$ One participant did not choose payment scheme for the third stage in math, and two did not perform in this stage. In the word task, two participants did not choose payment scheme. When possible, these individuals are included in the analysis. Including or excluding these participants has no effect on the results.

${ }^{22}$ A sample size analysis indicates that 2037 observations would be needed to obtain a significant result for the gender gap in competition choice in word search. The basis for the power calculation is a significance level of $5 \%$ and a power of $80 \%$.
} 
$\mathrm{p}=0.659) .{ }^{23}$ When we compare boys and girls, girls are significantly more underconfident in the verbal task $(\mathrm{p}<0.001)$, and there is some evidence that girls are more underconfident in math $(\mathrm{p}=0.097)$. This is interesting given that most studies on college students find that both boys and girls are overconfident. ${ }^{24}$

Table 5. Distribution of guessed ranks.

\begin{tabular}{|c|c|c|c|c|c|c|}
\hline & \multicolumn{3}{|c|}{ Men } & \multicolumn{3}{|c|}{ Women } \\
\hline & $\begin{array}{c}\text { Guessed } \\
\text { rank }\end{array}$ & $\begin{array}{c}\text { Over- } \\
\text { confident }\end{array}$ & $\begin{array}{c}\text { Under- } \\
\text { confident }\end{array}$ & $\begin{array}{c}\text { Guessed } \\
\text { rank }\end{array}$ & $\begin{array}{c}\text { Over- } \\
\text { confident }\end{array}$ & $\begin{array}{c}\text { Under- } \\
\text { confident }\end{array}$ \\
\hline \multicolumn{7}{|l|}{ Math } \\
\hline 1. Best & $9(5)$ & 4 & - & $3(2)$ & 1 & - \\
\hline 2. & $23(9)$ & 8 & 6 & $16(4)$ & 8 & 4 \\
\hline 3. & 30 (10) & 7 & 13 & 31 (5) & 10 & 16 \\
\hline 4. Worst & $18(6)$ & - & 12 & 41 (17) & - & 24 \\
\hline Total & 80 & & & 91 & & \\
\hline \multicolumn{7}{|l|}{ Word } \\
\hline 1. Best & 11 (3) & 8 & - & $1(1)$ & 0 & - \\
\hline 2. & $25(7)$ & 11 & 7 & $22(6)$ & 4 & 12 \\
\hline 3. & 30 (13) & 8 & 9 & 46 (13) & 9 & 24 \\
\hline 4. Worst & $14(6)$ & - & 8 & 21 (10) & - & 11 \\
\hline Total & 80 & & & 90 & & \\
\hline
\end{tabular}

*Number of correct guessed in parenthesis.

Individual risk preferences as well as relative performance beliefs have previously been found to influence competitive choices (e.g. Niederle och Vesterlund 2007; Niederle and Yestrumskas 2008). Looking at risk preferences in our incentivized risk task, girls in our sample who self-select into competition are significantly more risk taking than other girls in both the mathematical task ( $\mathrm{p}=0.049)$ and the verbal task $(\mathrm{p}=0.004)$. For boys, there is a significant difference in risk taking between those who compete and those who do not only in math $(\mathrm{p}=0.009)$. However, exploring the self-reported risk measure, the only significant difference is when comparing boys choosing to compete or not in math $(\mathrm{p}=0.006)$.

\footnotetext{
23 A t-test indicates that boys are significantly underconfident in math $(\mathrm{p}=0.041)$. Our measure of over/underconfidence is the difference between relative performance beliefs and actual relative performance, both in terms of quartile in the performance distribution. When assigning individuals to a quartile for actual relative performance, we divide each separate class into four equal groups (roughly equal groups when the class size cannot be divided by four). In some cases several individuals performed equally across groups. Those individuals are given an expected quartile. For example, if four individuals perform similarly, and two needs to be assigned to the worst quartile and two to the second to worst quartile, these individuals all received the expected quartile 3.5 .

${ }^{24}$ However, in a study of confidence in math performance among 14-year old children in Sweden, Dahlbom et al. (2011) find that boys are overconfident and girls are underconfident. While we ask our participants about retrospective performance, Dahlbom et al. (2011) ask the children about their expected performance on a math test that will be performed later. The confidence measures also differ between the two studies.
} 
Conducting a regression analysis analyzing the gender gap in competitive choices we perform four regressions per task, stepwise including control variables such as relative performance beliefs and risk preferences as can be seen in table 6 (math) and 7 (word) below. ${ }^{25}$ We analyze the full sample of individuals, however 45 participants (two classes) were not asked to state their performance beliefs regarding stage 2 performance. We thus also analyze a restricted sample excluding these individuals and those for whom we don't have all control variables. The results are very similar. In math, we find that controlling for actual individual performance and the average performance of the class diminishes the size of the observed gender gap with only 5\% in the restricted sample (comparing the coefficients in regression 1 and regression 3 in Table 6). When comparing regression 1 with regression 5 in the restricted sample, i.e. also adding controls for relative performance beliefs and risk preferences, we see that the gender difference in competitive choice in math is no longer significant. The point estimate of the female coefficient is lower, but still negative. The four control variables account for about $50 \%$ of the gender gap found in regression 1 . Performance beliefs account for about $32 \%$ of the observed gender gap and risk preferences for about $13 \%$. This can be compared to the results reported in Niederle and Vesterlund (2007), who find that $27 \%$ of the gender gap in tournament entry in their sample can be attributed to differences in relative performance beliefs. ${ }^{26}$ Including a control for risk preferences instead of performance beliefs does not eliminate the significant gender gap in tournament entry in math. When performing a regression analysis including the controls female, class mean performance, performance and risk preferences, the female coefficient remains significant in the restricted sample $(p=0.029)$ as well as in the full sample $(\mathrm{p}=0.013){ }^{27}$

The gender gap in tournament choice in the verbal task is not significant, independent of whether we control for performance or not. Performance beliefs and risk taking are, as in math, positively related to choosing to compete in the verbal task.

\footnotetext{
${ }^{25}$ Note that the regression analysis is based on parametric assumptions that may not be fulfilled. However, the gender gap in the regression analysis is similar to that found with the non-parametric tests.

${ }^{26}$ The setups of our study and that of Niederle and Vesterlund (2007) differ in that they had participants submit a piece-rate performance to the tournament, whereas in our case participants performed again when choosing to compete. Moreover, Niederle and Vesterlund find that gender differences in risk preferences only have a negligible effect on the choice to compete.

${ }^{27}$ We include class mean performance since performance beliefs are relative to other individuals' performance in the class.
} 
Table 6. Math: Logit regression ${ }^{28}$

\begin{tabular}{|c|c|c|c|c|c|c|c|c|}
\hline \multirow[b]{2}{*}{ Variables } & \multicolumn{5}{|c|}{ Math (restricted sample) } & \multicolumn{3}{|c|}{ Math (full sample) } \\
\hline & 1 & 2 & 3 & 4 & 5 & 6 & 7 & 8 \\
\hline Female & $\begin{array}{c}-0.191^{* *} \\
(0.069)\end{array}$ & $\begin{array}{c}-0.213^{* *} \\
(0.073)\end{array}$ & $\begin{array}{l}-0.182 * \\
(0.078)\end{array}$ & $\begin{array}{l}-0.121 \\
(0.078)\end{array}$ & $\begin{array}{l}-0.096 \\
(0.074)\end{array}$ & $\begin{array}{c}-0.193^{* *} \\
(0.059)\end{array}$ & $\begin{array}{c}-0.206 * * \\
(0.060)\end{array}$ & $\begin{array}{c}-0.171^{* *} \\
(0.062)\end{array}$ \\
\hline Class mean & & $\begin{array}{l}-0.030 \\
(0.031)\end{array}$ & $\begin{array}{l}-0.049 \\
(0.032)\end{array}$ & $\begin{array}{l}-0.037 \\
(0.031)\end{array}$ & $\begin{array}{l}-0.043 \\
(0.029)\end{array}$ & & $\begin{array}{l}-0.025 \\
(0.025)\end{array}$ & $\begin{array}{l}-0.049 \\
(0.026)\end{array}$ \\
\hline Performance & & & $\begin{array}{l}0.037^{* *} \\
(0.010)\end{array}$ & $\begin{array}{l}0.021 * \\
(0.010)\end{array}$ & $\begin{array}{c}0.017 \\
(0.009)\end{array}$ & & & $\begin{array}{c}0.038^{* *} \\
(0.009)\end{array}$ \\
\hline Beliefs & & & & $\begin{array}{c}0.152 * * \\
(0.041)\end{array}$ & $\begin{array}{c}0.156^{* *} \\
(0.041)\end{array}$ & & & \\
\hline Risk & & & & & $\begin{array}{c}0.071^{* *} \\
(0.026)\end{array}$ & & & \\
\hline
\end{tabular}

$\begin{array}{lllllllll}\text { Observations } & 169 & 169 & 169 & 169 & 169 & 215 & 215 & 215\end{array}$

Marginal effects calculated at the mean. Robust standard errors in parentheses. ${ }^{*} \mathrm{p}<0.05,{ }^{* *} \mathrm{p}<0.01 .45$ participants were not asked to state their beliefs about second stage performance, one participant did not answer the risk question and one did not choose payment scheme.

Table 7. Word: Logit regression controlling for performance, beliefs and risk preferences

\begin{tabular}{|c|c|c|c|c|c|c|c|c|}
\hline \multirow[b]{2}{*}{ Variables } & \multicolumn{5}{|c|}{ Word (restricted sample) } & \multicolumn{3}{|c|}{ Word (full sample) } \\
\hline & 1 & 2 & 3 & 4 & 5 & 6 & 7 & 8 \\
\hline Female & $\begin{array}{l}-0.056 \\
(0.073)\end{array}$ & $\begin{array}{l}-0.059 \\
(0.080)\end{array}$ & $\begin{array}{l}-0.064 \\
(0.080)\end{array}$ & $\begin{array}{c}0.037 \\
(0.085)\end{array}$ & $\begin{array}{c}0.057 \\
(0.086)\end{array}$ & $\begin{array}{l}-0.058 \\
(0.063)\end{array}$ & $\begin{array}{l}-0.063 \\
(0.065)\end{array}$ & $\begin{array}{l}-0.068 \\
(0.065)\end{array}$ \\
\hline Class mean & & $\begin{array}{l}-0.005 \\
(0.038)\end{array}$ & $\begin{array}{l}-0.013 \\
(0.039)\end{array}$ & $\begin{array}{l}-0.018 \\
(0.039)\end{array}$ & $\begin{array}{l}-0.049 \\
(0.042)\end{array}$ & & $\begin{array}{l}-0.008 \\
(0.028)\end{array}$ & $\begin{array}{l}-0.014 \\
(0.029)\end{array}$ \\
\hline Performance & & & $\begin{array}{c}0.017 \\
(0.010)\end{array}$ & $\begin{array}{l}-0.006 \\
(0.011)\end{array}$ & $\begin{array}{c}-0.004 \\
(0.010)\end{array}$ & & & $\begin{array}{c}0.010 \\
(0.008)\end{array}$ \\
\hline Beliefs & & & & $\begin{array}{c}0.246^{* *} \\
(0.055)\end{array}$ & $\begin{array}{c}0.244^{* *} \\
(0.055)\end{array}$ & & & \\
\hline Risk & & & & & $\begin{array}{c}0.080^{* *} \\
(0.028)\end{array}$ & & & \\
\hline Observations & 167 & 167 & 167 & 167 & 167 & 214 & 214 & 214 \\
\hline
\end{tabular}

\footnotetext{
${ }^{28}$ Performance and beliefs in the regression analysis is based on performance and relative performance beliefs in the second stage (the tournament). Using performance in the third stage instead of performance in the second stage does not qualitatively change our gender results. Since 15 participants were inconsistent in their choices in the risk task, the risk measure included here is the number of risky choices the participants make. Moreover, OLS specifications provide qualitatively similar results for Table 6 and Table 7.
} 


\subsection{Summary of results}

In sum, we find that among adolescents, girls give more in a dictator game where the recipient is a charity, and that boys are more risk taking than girls. We find no gender gap in performance change when our participants are forced to compete. Boys and girls are equally likely to choose to compete in a verbal task, but boys are significantly more likely to choose to compete in a mathematical task. However, this gender difference diminishes and becomes insignificant when we control for relative performance beliefs.

\section{Discussion}

The gender gap in preferences has recently been suggested as an explanation for the often observed gender differences in labor market outcomes. Studies on children and adults suggest that if there is any gender gap in economic preferences, it is the most robust for altruism, risk and competition; girls and women are often more altruistic, less risk taking and less competitive than boys and men. To what extent these findings are consistent across contexts, countries and age is something that is currently being investigated in a number of projects.

In this study we systematically explore the gender gap in these preferences among adolescents in Sweden. Relatively little is known about the development of the gender gap in economic preferences, and to what extent adolescents exhibit the same type of gender differences in preferences as adults do. For example, it is generally acknowledged that the teenage years are associated with increased risk seeking (Boyer 2006). At the same time, many important decisions during this period have lifelong consequences, for example pertaining to education and professional choice. Policies aiming at reducing the gender gap in the labor market may thus be relevant also before labor market entry.

In this study, we find that adolescent girls are more altruistic and less risk taking than adolescent boys, corroborating the general findings on adults as well as some previous findings among adolescents. When it comes to competitiveness, we find no gender gap in performance change in either a mathematical task or a verbal task, comparing performance in a forced tournament to performance in a piece-rate scheme. We also find no gender gap in the choice whether to compete or not in the verbal task. In math, boys are more likely to choose to compete than girls, a finding in line with other studies on children (Sutter and Rützler 2010) and adults (e.g. Niederle and Vesterlund 2007). However, once we control for performance beliefs, this gap diminishes and becomes non-significant, indicating that a large part of the observed gender gap in our sample does not depend on a gender difference in 
preference for competition per se. Support for this is also given by studies on adults, which shows that the gender gap in competitiveness can be eliminated by performance feedback (Wozniak et al. 2010), repetition (Cotton et al. 2009) or in environments where uncertainty is minimized (Niederle and Yestrumskas 2008). Why we find no gender gap in selection into competition in the verbal task is puzzling given that the gender gap in underconfidence was even stronger for this task than for math. This lends some support for the importance of tasks when studying competitiveness.

Our results, in relation to previous literature, thus suggest that the gender gap in risk taking, and perhaps also in altruism, emerges before adulthood. The results on competitiveness are less conclusive and appear to be influenced by performance beliefs, and the potential development of this gender gap remains to be explored further. Moreover, we study adolescents in Sweden, a country that typically scores among the highest on gender equality indices. To what extent our results are generalizable to adolescents in other countries and settings is thus not clear. In sum, more research is needed in order to establish when and why gender differences in preferences arise, as well as their exact implications for the labor market.

\section{References}

Almås, I., Cappelen, A.W., Sørensen, E.Ø., \& Tungodden, B. (2010). Fairness and the development of inequality acceptance. Science, 328, 1176-1178.

Andersen, S., Ertac, S., Gneezy, U., List, J., \& Maximiano, S. (2010). Age and gender differences in competitiveness: evidence from matrilineal and patriarchal societies. Mimeo.

Benenson, J.F., Pascoe, J., \& Radmore, N. (2007). Children's altruistic behavior in the dictator game. Evolution and Human Behavior, 28(3), 168-175.

Blake. P.R., \& Rand, D.G. (2010). Currency value moderates equity preference among young children. Evolution and Human Behavior, 31, 210-218.

Bonin, H., Dohmen, T., Falk, A., Huffman, D., \& Sunde, U. (2007). Cross-sectional earnings risk and occupational sorting: the role of risk attitudes. Labour Economics, 14(6), 926-937.

Bolton, G., \& Katok, E. (1995). An experimental test for gender differences in beneficent behavior. Economics Letters, 48, 287-292.

Booth, A.L., \& Nolen, P.J. (2009). Choosing to compete: how different are girls and boys? IZA Discussion Paper 4027.

Booth, A.L., \& Nolen, P.J. (2012). Gender differences in risk behaviour: does nurture matter? Economic Journal, 122(558), F56-F78. 
Borghans, L., Golsteyn, B.H.H., Heckman, J.J., \& Meijers, H. Forthcoming. Gender differences in risk aversion and ambiguity aversion. Journal of the European Economic Association.

Boyer, T. (2006). The development of risk-taking: a multi-perspective view. Developmental Review, 26, 291-345.

Cárdenas, J.-C., Dreber, A., von Essen, E., \& Ranehill, E. (2012). Gender differences in competitiveness and risk taking: comparing children in Colombia and Sweden. Journal of Economic Behavior and Organization, 83(1), 11-24.

Cotton, C., McIntyre, F., \& Price, J. (2009). Gender differences disappear with exposure to competition. Working Paper 2010-11, University of Miami, Department of Economics.

Croson, R., \& Gneezy, U. (2009). Gender differences in preferences. Journal of Economic Literature, 47(2), 1-27.

Dahlbom L., Jakobsson, A., Jakobsson, N., \& Kotsadam, A. (2011). Gender and overconfidence: are girls really overconfident? Applied Economics Letters, 18(4), 325-327.

Datta Gupta, N., Poulsen, A., \& Villeval, M.-C. In press. Gender matching and competitiveness: experimental evidence. Economic Inquiry.

Dohmen, T., Falk, A., Huffman, D., Sunde, U., Schupp, J., \& Wagner, G.G. (2011). Individual risk attitudes: measurement, determinants and behavioral consequences. Journal of the European Economic Association, 9(3), 522-550.

Dreber, A., von Essen, E., \& Ranehill, E. (2011). Outrunning the gender gap: boys and girls compete equally. Experimental Economics, 14(4), 567-582.

Eckel, C., \& Grossman, P. (2008a). Men, women and risk aversion: experimental evidence. In C. Plott and V. Smith (Ed.), Handbook on experimental economics results (pp. 1063-1071). New York: Elsevier.

Eckel, C., \& Grossman, P. (2008b). Differences in the economic decisions of men and women: experimental evidence. . In C. Plott and V. Smith (Ed.), Handbook on experimental economics results (pp. 509-519). New York: Elsevier.

Engel, C. (2011). Dictator games: a meta study. Experimental Economics, 14(4), 583-610.

Fehr, E., Rützler, D., \& Sutter, M. (2011). The development of egalitarianism, altruism, spite and parochialism in childhood and adolescence. IZA Discussion Paper 5530.

Flory, J., Leibbrandt, A., \& List, J. (2010). Do competitive work places deter female workers? A large-scale natural field experiment on gender differences in job-entry decisions. NBER Working Paper Series w16546.

Fortin, N.M. (2008). The gender wage gap among young adults in the United States. Journal of Human Resources, 43(4), 884-918.

Gneezy, U., Leonard, K., \& List, J. (2009). Gender differences in competition: evidence from a matrilineal and a patriarchal society. Econometrica, 77(5), 1637-1664. 
Gneezy, U., Niederle, M., \& Rustichini, A. (2003). Performance in competitive environments: gender differences. Quarterly Journal of Economics, 118(3), 1049-1074.

Gneezy, U., \& Rustichini, A. (2004a). Gender and competition at a young age. American Economic Review, 94(2), 377-381.

Gneezy, U., \& Rustichini, A. (2004b). Executives verses teachers: gender, competition and self selection.” Mimeo.

Gong, B., \& Yang, C.-L.. (2012). Gender differences in risk attitudes: field experiments on the matrilineal Mosuo and the patriarchal Yi. Journal of Economic Behavior and Organization, 83(1), 59-65.

Grosse, N.D., \& Reiner, G. (2010). Explaining gender differences in competitiveness: gendertask stereotypes. Jena Economic Research Papers 2010 - 017.

Guiso, L., Monte, F., Sapienza, P., \& Zingales, L. (2008). Culture, gender, and math. Science, 320(2880), 1164-1165.

Gummerum, M., Hanoch, Y., Keller, M., Parsons, K., \& Hummel, A. (2010). Preschoolers‘ allocations in the dictator game: the role of moral emotions. Journal of Economic Psychology, 31(1), 25-34.

Günther, C., Arslan Ekinici, N., Schwieren, C., \& Strobel, M. (2009). Women can’t jump? an experiment on competitive attitudes and stereotype threat. Journal of Economic Behavior and Organization, 75(3), 395-401.

Harbaugh, W.T., Krause, K., \& Vesterlund, L. (2002). Risk attitudes of children and adults: choices over small and large probability gains and losses. Experimental Economics, 5(1), 5384.

Harbaugh, W.T., Krause, K., \& Liday, S.G. Jr. (2003). Bargaining by children. Working Paper, University of Oregon.

Manning, A., \& Farzad, S. (2010). Understanding the gender pay gap: what's competition got to do with it? Industrial and Labor Relations Review, 63(4), 681-698.

Manning, A., \& Swaffield, J. (2008). The gender gap in early-career wage growth. Economic Journal, 118, 983-1024.

Martinsson, P., Nordblom, K., Rützler, D., \& Sutter, M. (2011). Social preferences during childhood and the role of gender and age - an experiment in Austria and Sweden. Economics Letters, 110(3), 248-251.

Niederle, M., \& Vesterlund, L. (2007). Do women shy away from competition? Do men compete too much? Quarterly Journal of Economics, 122(3), 1067-1101.

Niederle, M., \& Yestrumskas, A.H. (2008). Gender differences in seeking challenges: the role of institutions. Mimeo.

Shurchkov, O. Forthcoming. Under pressure: gender differences in output quality and quantity under competition and time constraints. Journal of the European Economic Association. 
Sutter, M., \& Rützler, D. (2010). Gender differences in competition emerge early in life. IZA Discussion Paper 5015.

Sutter, M., Feri, F., Kocher, M.G., Martinsson, P., Nordblom, K., \& Rützler, D. (2010). Social preferences in childhood and adolescence: a large-scale experiment. IZA Discussion Paper 5016.

Sutter, M., Kocher, M.G., Rützler, D., \& Trautmann, S.T. Forthcoming. Impatience and uncertainty: experimental decisions predict adolescents' field behavior. American Economic Review.

Wozniak, D., Harbaugh, W., \& Mayr, U. (2010). Choices about competition: differences by gender and hormonal fluctuations, and the role of relative performance feedback. MPRA Paper 21097.

Zhang, J. (2010). Do girls in China compete just as much as boys? Evidence from an experiment that predicts educational choice. Mimeo. 